\title{
EMBRYONAL HEPATOMA IN JAPAN: PATHOLOGICAL STUDY ON 19 CASES OF HEPATIC CARCINOMA IN INFANCY AND CHILDHOOD*
}

\author{
HIROSHI WATANABE and TADAYOSHI KOBAYASHI** \\ Department of Pathology, School of Medicine \\ Keio University
}

(Received for publication June 16, 1961)

Primary carcinoma of the liver is generally considered to be not uncommon in adult and on the contrary extremely rare in infancy and childhood. By reason of the fact that there were only two cases of carcinoma of the liver reported in children, both from Japan, in reviews of the two excellent papers published by Steiner(1) and by Bieglow, (2) Edmondson(3) ${ }^{(3)}$ stated that there was a strange absence of reported cases of carcinoma of the liver in infancy and childhood in the parts of the world where there was a high frequency of liver carcinoma and all other cases appeared to be from sections of the world where primary carcinoma in the liver was uncommon. However more than 40 cases of hepatic carcinoma in infancy and childhood had been reported in Japanese literature since Yamagiwa's case.

Mesenchymal tissue elements, for example bone or osteoid tissue, cartilage and so on were occasionally observed by many investigators in tumor tissue of primary hepatic carcinoma in infancy and childhood, in other words, embryonal hepatoma. It is therefore plausible that the differentiation between embryonal hepatoma and true mixed tumor of the liver is still controversial.

The pathological study on 19 cases of embryonal hepatoma which have been recently autopsied in Japan is presented in this paper.

\section{MATERIAL AND METHOD}

Pathological studies on embryonal hepatoma were performed on the basis of 19 cases which have been recently autopsied or of which gross specimens have been well preserved for gross and histological examination. The large hepatic tissue including both lobes, approximately central cut surface of $2-3 \mathrm{~cm}$ in

* This study was supported in parts by Grant in Aid for Foundamental Scientific Research.

** Professor of Pathology. 


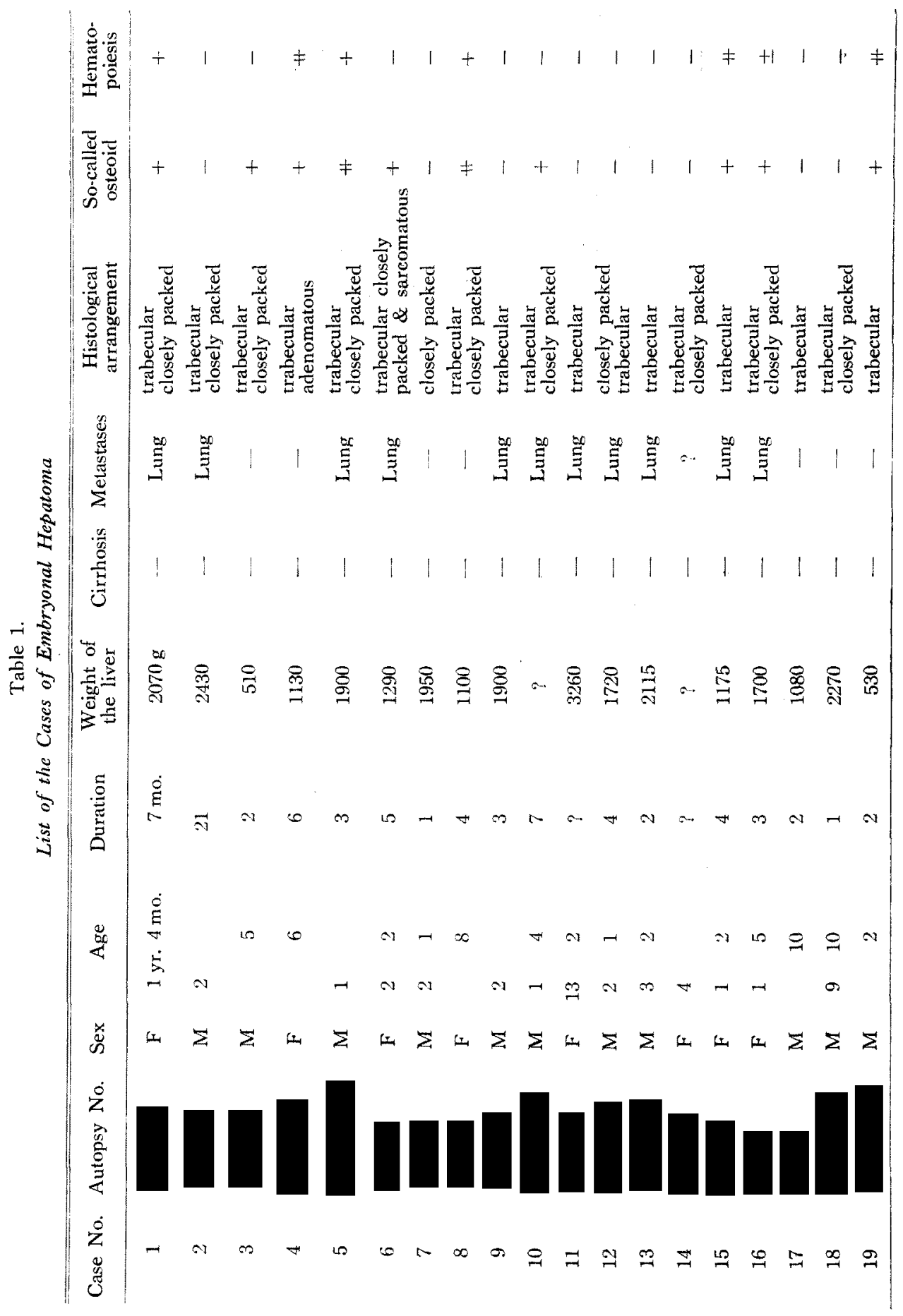


thickness, of these cases were submitted from the pathological departments of 12 medical schools and 1 hospital throughout Japan.

After routine gross examination, large section specimens of submitted entire material mounted on the paper were prepared by the modified method of Gough and Wentworth by Sano(4) using carbonic acid gas freezing instead of refrigerator and their thin slices were stained by hematoxylin-eosin, nile-blue staining etc. Then several different pieces in appearance containing tumor, apparently normal and their border tissue were taken for histological study with various staining.

\section{RESULTS AND COMMENT}

The general data, gross and microscopical findings of the cases for the present study are briefly summarized as indicated in Table 1. Since Yamagiwa's case in 1911, 40 cases of embryonal hepatoma, including surgical biopsy cases, reported from or in Japan are listed in Table 2. In 193877 autopsy cases, including reported from Japan, of primary hepatic carcinoma in childhood with ages up to 16 years were reviewed by Steiner and also in 195395 cases including 74 cases collected by Steiner were discussed by Bieglow and Wright. Recently 5 cases in 1958 which consist of Case No. 2, 3, 5, 7 and 8 in Table 1 and 3 cases in 1959 of embroynal hepatoma were recorded in Annual(5) of the Pathological Autopsy Cases in Japan edited by Japanese Pathological Society. These cases are summarized as follows in comparison with their incidence in the United States:

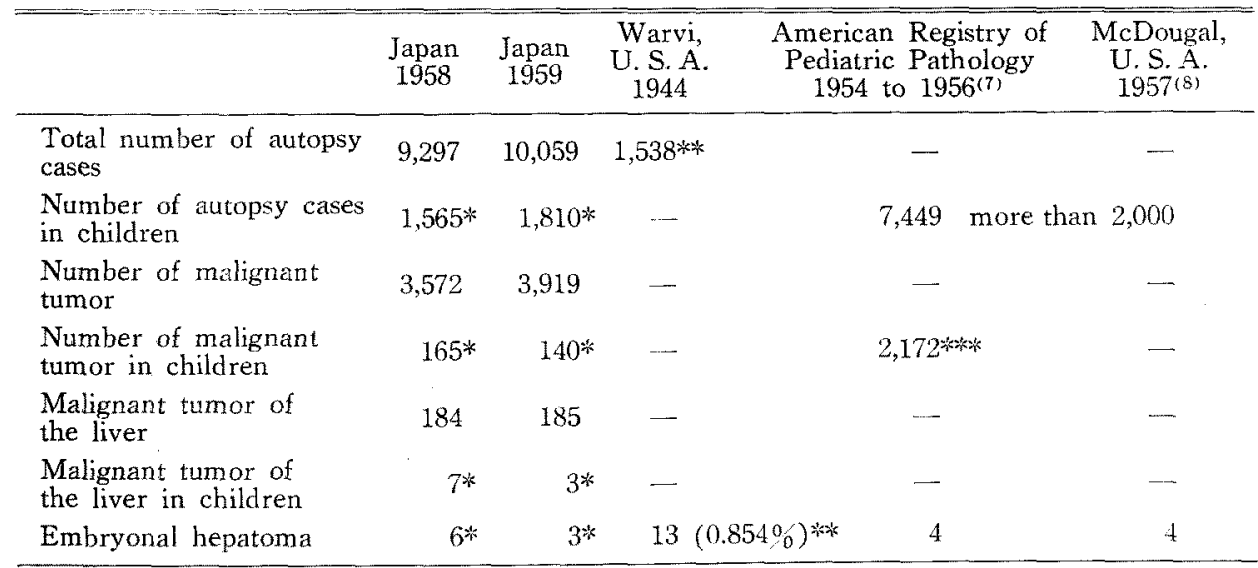

\footnotetext{
* under 9 years of age

** autopsy incidence of primary carcinoma of the liver in children in U.S. A., introduced in Jone's paper ${ }^{(6)}$

*** all tumor types
} 


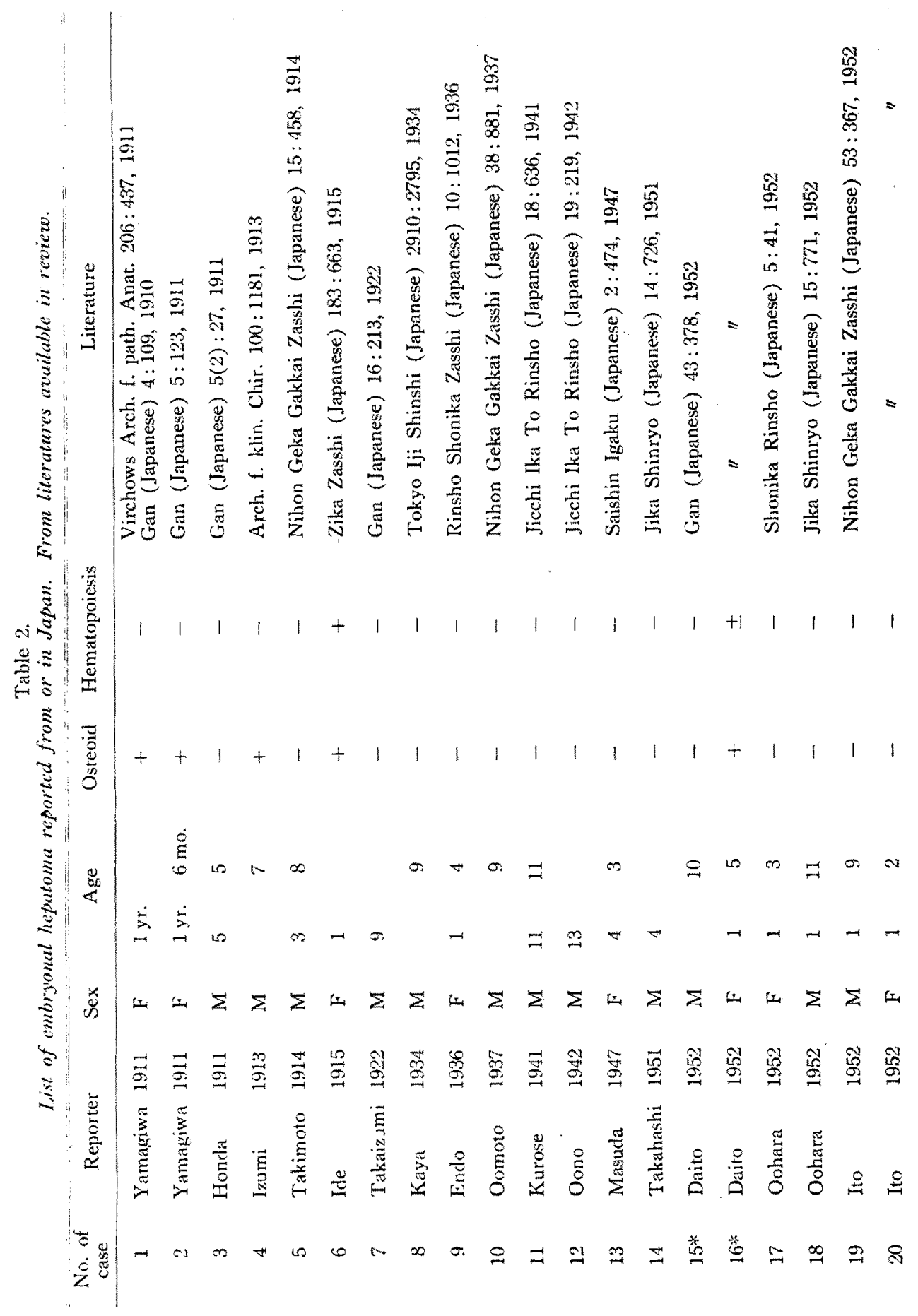




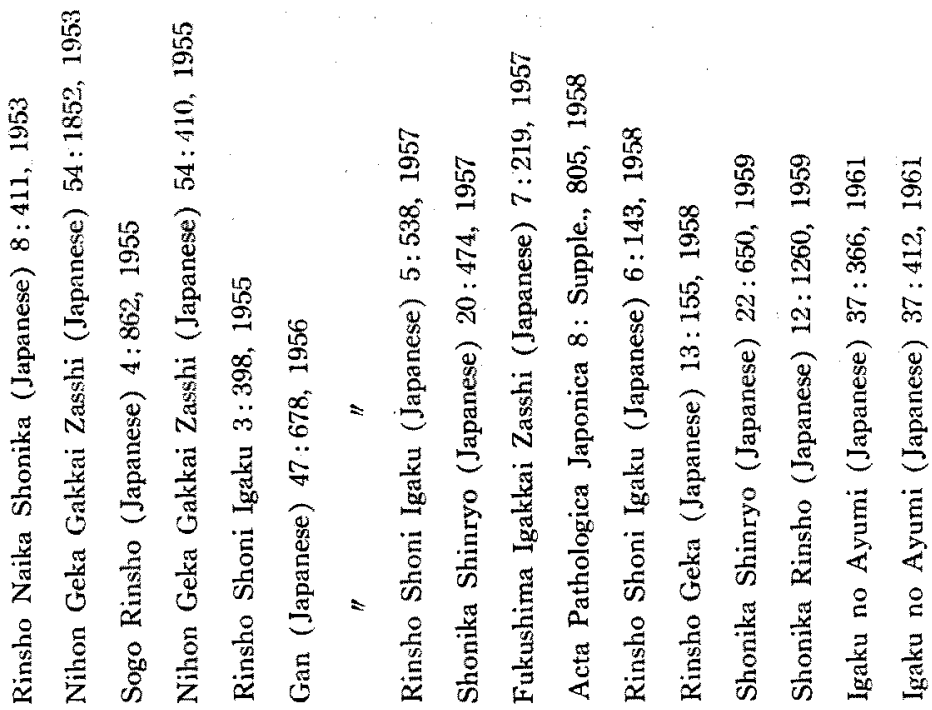

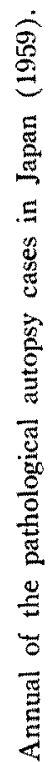

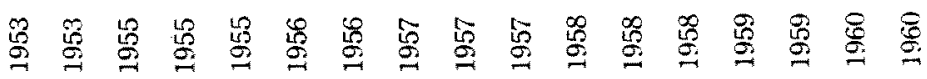


Concerning the incidence of embryonal hepatoma in Japan and the United States, it may be roughly concluded in spite of Edmondson's statement that the significant tendency in geographical distribution of embryonal hepatoma seems to be unlikely postulated.

The geographical distribution of the cases in the present study is as follows and demonstrated in Figure 1:5 cases from Tokyo area, 1 Osaka area, 1 Nagoya area, 8 Tohoku district (northern part of Japan), 1 Hokuriku district, 2 Yamaguchi district and 1 Kagoshima area (southmost city of Japan). All cases listed in Table 2 were distributed similarily in proportion throughout Japan.

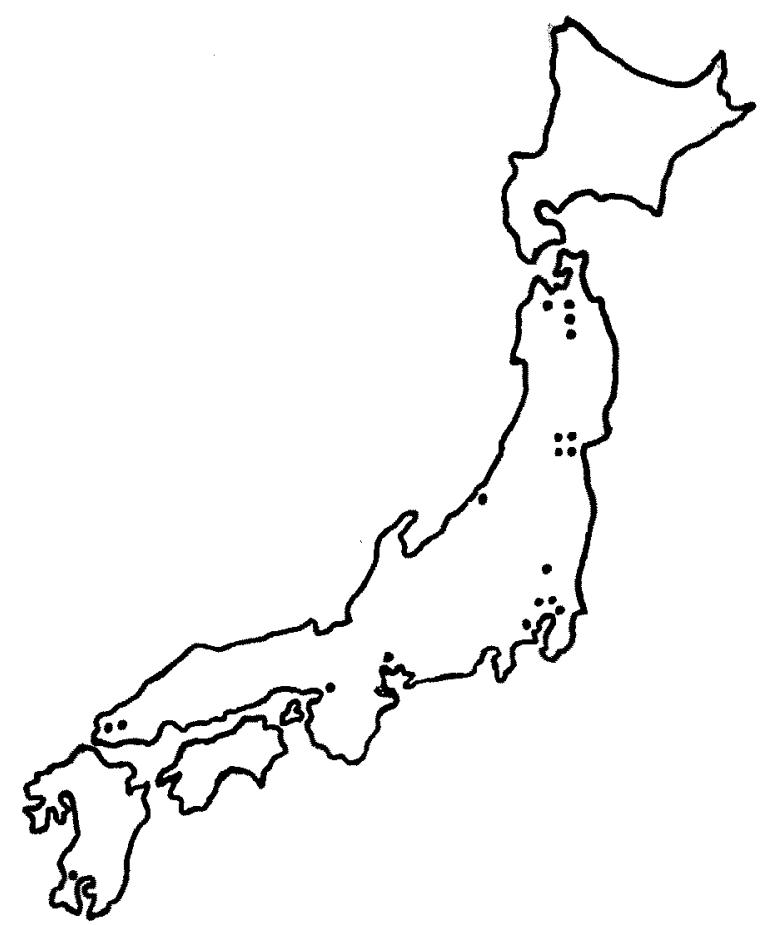

Fig. 1. Geographical distribution of the submitted cases of embryonal hepatoma in Japan.

The studied cases of embryonal hepatoma consist of 11 boys and 8 girls and the reviewed cases in Table 227 boys and 13 girls. Jones described $58.91 \%$ for males and $34.8 \%$ for female on sex incidence in 129 cases of primary carcinoma of the liver in infants and children in a survey of literature of the past 102 years.

It is recorded in Table 1 that 15 cases among 19 are under 3 years of age. Case No. 13 is added to this group, considering the duration of the illness. Also Table 2 shows 28 cases under 3 years of age. The majority of these tumor 
is predominantly noticed under 2 years of age in Steiner's, Bieglow's and Jones' reviews.

The enlargement of the liver is prominently noticed in the almost all cases of the present study and weight of the liver is usually four or five times than normal. All liver specimens are roughly classified in gross appearance as nodular and massive type. The liver is largely replaced by many almostly same sized nodules (Fig. 2) or by the main tumor with small nodvles in the surrounding tissue (Fig. 3). Every tumor nodules arc somewhat encapsulated and the tumors usually grow in an expansile fashion. Tumor tissue contains a few fibrous strands and is soft and friable in palpation. Although the collected specimens were already fixed by formalin and they give not so striking colour as unfixed stage, hemorrhage, necrosis, bile staining and yellow tinge are distinctly observed in tumor tissue. In Case No. 14 was observed thrombus formation consisted of soft and gray necrotic tissue with hemorrhage, possibly tumor thrombus, in large intrahepatic vein. On the large section specimens without staining of Case No. 5 minimal portion which seems grossly to be bone or osteoid tissuz in consistency and appearance is indicated to be more irregularly spread and semitransparent than the usual fibrous strands. The several small pieces of this portion are removed for the specific histological observation.

Primary carcinoma of the liver in Japan was surveyed by Miyaji(9) on the basis of 38,145 autopsy cases. In the survey $40.4 \%$ of hepatic carcinoma of which the majority was adult case are described to be associated with hepatic cirrhosis. Jones discussed 7 cases collected from the literature and 1 original of associated hepatic cirrnosis of the 128 cases of primary liver carcinoma in infancy and childhood. It is, however, well known that the concomitant hepatic cirrhosis with carcinoma in infants and children has been described as being infrequent unlike adults. No association with hepatic cirrhosis is grossly and microscopically found in the present study.

Matastases in the lung is described in 11 among the studied cases and no metastatic growth in other organs and tissue except for that in perihepatic lymph nodes. Metastases in 129 cases of carcinoma of the liver in infants and children were listed in Jones' review as follows; lung 31 , brain 3 , lymph nodes 9 , spleen 2, humerus 1 , pancreas 1 , pericardium 1 , none 12 and not noted 67 .

It is shown in histological observation on 19 cases of the present study that the cytological characteristics of the tumor cells of embryonal hepatoma vary in the distinguishable features of cells, such as quantity and acidophilic quality of cytoplasm, the size and degree of hyperchromatism of the nuclei and the proportion of cell occupied by the nucleus compared to the amount of crto- 
plasm, from easily recognizable differentiated types with similarity to hepatic cord cells to highly anaplastic tumor cells. Tumor cells which present a few characteristics of cytological malignancy show usually trabecular arrangement with rich vascularity and resemblance to the structure of hepatic cords. Tubular or adenomatous patterns are predominantly recognized in some of the cases. It is another characteristic that the groups of tumor cells which are more anaplastic and of which cytoplasm is neither as abundant nor as acidophilic as liver-cell-like appearance are found to replace partially or entirely the tumor tissue. Such anaplastic cells are smaller in size, more spindle in shape and arranged in closely packed fashion with inconspicuous capillaries. All of the collected cases are interpreted as liver cell type carcinoma and many of them are indicated in Table 1 to present mostly the cellular arrangement of : $_{\text {combined }}$ trabecular pattern with a various amount of closely packed pattern (Fig.4). In Steiner's, Bieglow's and Jones' survey of primary carcinoma of the liver in children were respectively $70.7 \%, 63.15 \%$ and $58.6 \%$ of the cases reported to be liver cell carcinoma.

The most striking structure in this survey of microscopical findings of embryonal hepatoma is the presence of small or large, circumscribed, irregular, homogenous masses which are usually stained pinkish by eosin, red or blue by Mallory's staining and have the appearance of osteoid or osseous tissue. Minute lacunar spaces in which are viable cells are observed especially in large one of such lesions. These so-called osteoid tissues are so frequently noticed to be included variably in size within tumor tissue as in 10 cases among 19 (Table 1). The depositions of the so-called osteoid or osseous tissue are usually observed within tumor tissue, though they are rarely found also in the fibrous stroma adjacent to the tumor. Even these lesions found in the supporting stroma of tumor appear to be continually traced fron those within tumor cell groups. The so-called osteoid tissues are prominently noticed in large quantities in some of the cases (Fig. 5) and they are occasionally purpled to be suggestive of calcification. The hyalinous fiber-like strands which are noticed to be irregularly thickened and illustrated by Figure 6 are considered to be the early stage of the so-called osteoid tissues within the tumor cell groups. No other mesenchymal tissue elements, such as cartilage, muscles, pigmentations, etc., which are described in many previous reports to be occasionally recognized in tumor tissue of embryonal hepatoma are observed inside or outside the neoplasm. It is another conspicuous finding that a various amount of hematopoiesis mainly composed of immature cells in erythrocytic series is scatteringly observed in relatively dilated sinusoids within tumor tissue of embryonal hepatoma (Fig. 7). 
These hematopoietic foci are found in 7 among 19 cases (Table 1 ).

It is generally considered that the presence of the so-called osteoid tissue is so frequently recognized in tumor tissue of embryonal hepatoma as shown in Table 2 and also as more than 50\% described by Bieglow. However few of descriptions are seen in the previous literature on the nature and mechanism of formation of such osteoid tissue and the presence of hematopoietic foci within the neoplasm of embryonal hepatoma. Moreover it is postulated from the histogenetic study on the particular histological findings of embryonal hepatoma in the present study that the so-called osteoid tissue might be essentially one of mere hyalinized changes, without any significant relation to bone tissue, of stromal connective tissue. The stromal hyalinization and the appearance of hematopoietic foci in embryonal hepatoma are also suggested to be genetically infuenced by the neoplastic cells originated from hepatic cells. Therefore both particular changes of embryonal hepatoma will be reported and discussed by the same authors in another paper with more detailed microscopical descriptions.

\section{SUMMARY}

1. The pathological study on 19 cases of embryonal hepatoma of which gross specimens were submitted from various parts in Japan was presented with a survey of 40 cases of embryonal hepatoma reported from Japan in literatures available in review.

2. Comparison of the incidence of embryonal hepatoma between Japan and the United States was briefly discussed and the geographical distribution of the submitted cases of embryonal hepatoma in Japan was recorded.

3. The majority of embryonal hepatoma was predominantly noticed under 3 years of age.

4. There was no specific relation between hepatic cirrhosis and primary carcinoma of the liver in infancy and chldhood unlike in adult.

5. Main metastatic growth of embryonal hepatoma was observed in the lung.

6. All cases of embryonal hepatoma in the present study were microscopically recognized as liver cell carcinoma and their histological arrangements were observed to be mostly trabecular combined with closely packed pattern.

7. The so-called osteoid tissue and hematopoietic foci within the neoplasm were described as conspicuous histologcial findings of embryonal hepatoma.

Grateful acknowledgement is made to Professors Akazaki (Tohoku Univ.), Fujimaki (Niigata Univ.), Hosokawa (Yamaguchi Univ.), Katsura (Iwate Univ.), Kawai (Gunma Univ.), Kawaji (Kagoshima Univ.), Miyagawa (Nagoya Univ.), Miyaji 
(Osaka Univ.), Ootaka (Tokyo Med. College) and Takizawa (Chiba Univ.) for the privilege of reviewing the necropsy records and generous supply of the autopsy material of embryonal hepatoma, and to Dr. Sano (Director of Department of Pathology, Institute for Science of Labour) for the preparing large section specimens of the submitted material.

\section{REFERENCES}

1. Steiner, M. M.: Primary carcinoma of the liver in childhood. Am. J. Dis. Child. 55: $807,1938$.

2. Bieglow, N. H.: Primary carcinoma of the liver in infancy and childhood. Cancer $6: 171,1953$.

3. Edmondson, H. A.: Tumors of the liver and intrahepatic bile ducts. A.F.I.P. Fascile 25, 1958.

4. Sano, T.: Modified method of preparing large section specimens and their staining method. J. of Science of Labour (Japanese). 36: 94, 1960.

5. Annual of the Pathological Autopsy Cases in Japan (1958). Japanese Pathological Society. Tokyo 1959 \& Annual of the Pathological Autopsy Cases in Japan (1959). Japanese Pathological Society. Tokyo 1960.

6. Jones, E.: Primary carcinoma of the liver with associated cirrhosis in infants and children. Arch. of Path. 70: 5, 1960.

7. Stowens, D.: Pediatric Pathology. Appendix. Williams \& Wilkins Comp. Baltimore 1959.

8. McDougal, R. A.: Primary carcinoma of the liver in infants and children. Cancer $10: 678,1957$.

9. Miyaji, T.: Pathological study on primary carcinoma of the liver in Japan for recent 10 years. Acta Hepatalgica Japonica (Japanese) 1: 17, 1960.

Literatures of embryonal hepatoma reported from Japan are listed in Table 2. 


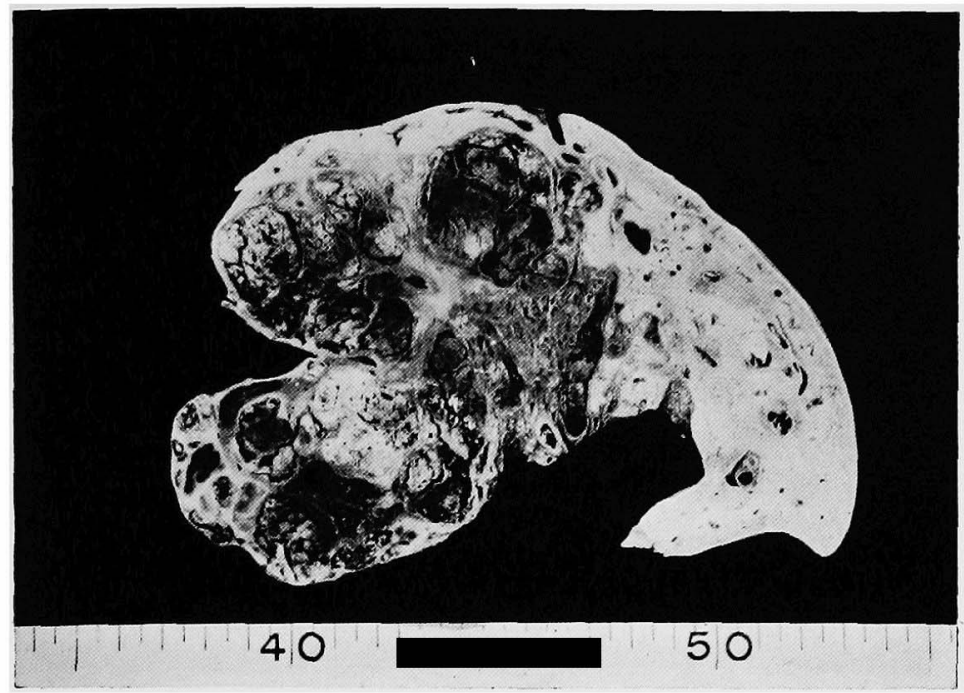

Fig. 2. Case No. 1.

Gross finding, many tumor nodules in the right lobe of the liver.

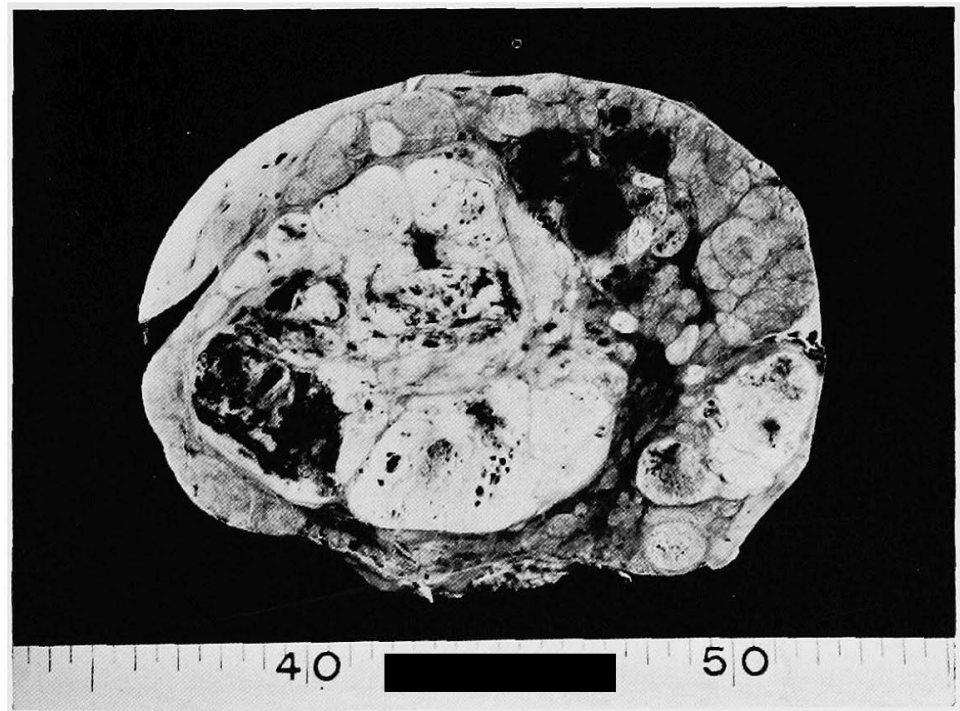

Fig. 3. Case No. 12 .

Gross finding, main tumor with small nodules in the surrounding tissue. 


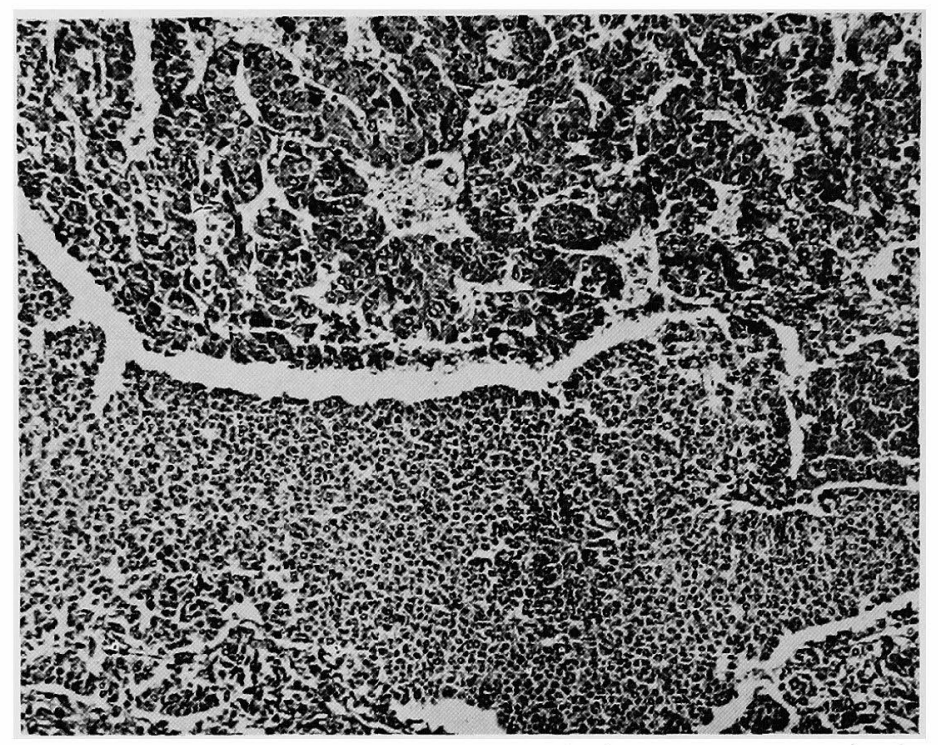

Fig. 4. Case No. 6.

Histological arrangement of trabecular pattern combined with closely packed fashion.

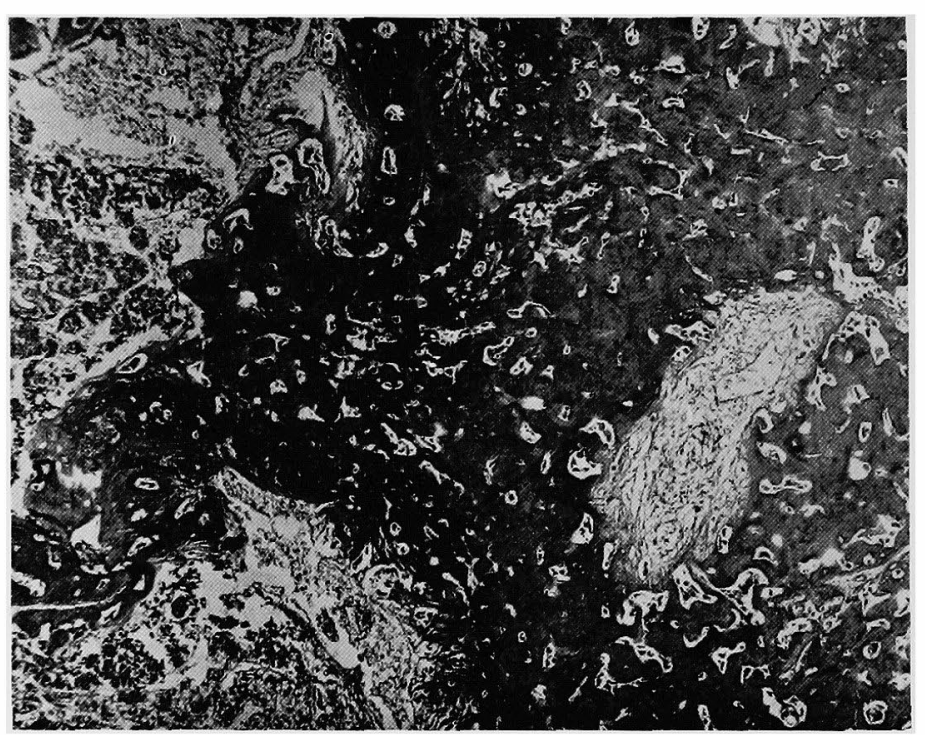

Fig. $5 . \quad$ Case- No. 8.

Presence of the so-called osteoid tissue in large quantities. 


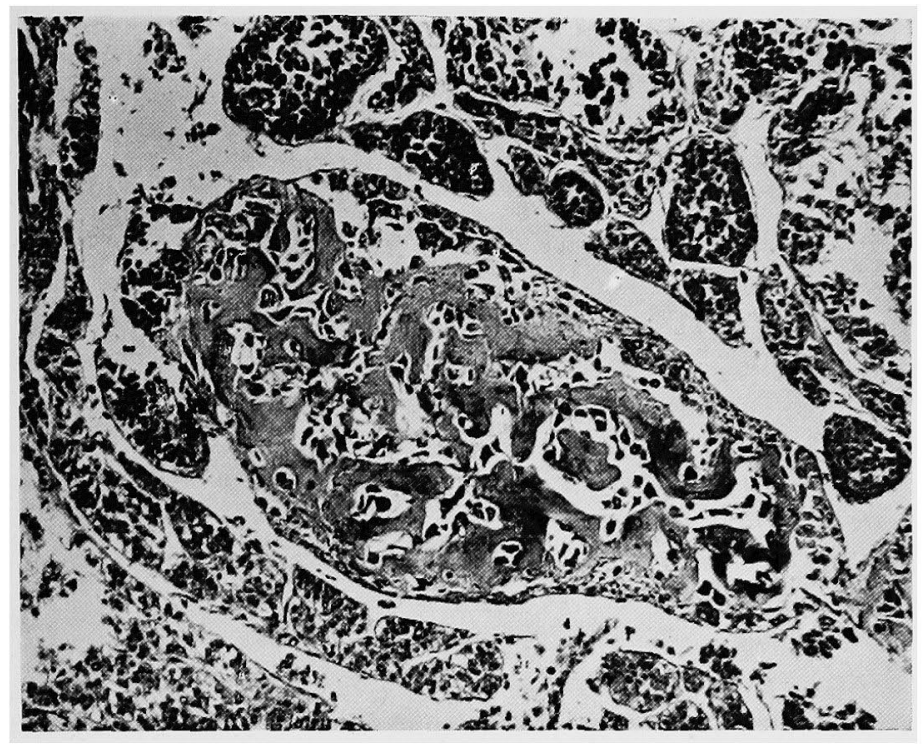

Fig. 6. Case No. 6.

Hyalinous fiber-like strands likely to be one of early stage of the so-called osteoid tissue.

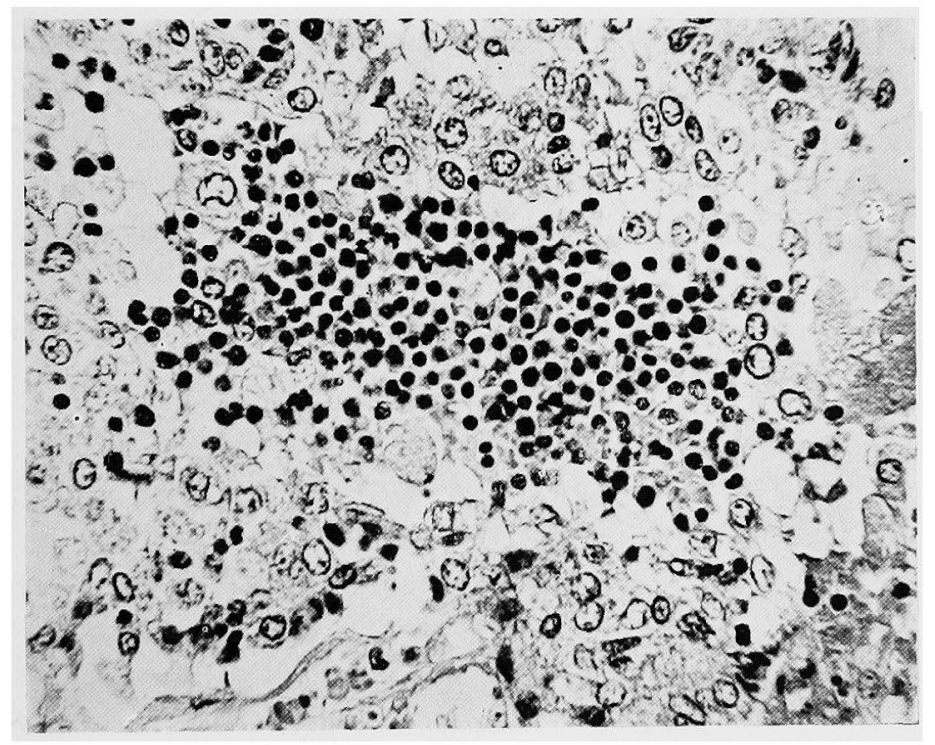

Fig. 7. Case No. 15.

Hematopoietic foci predominantly composed of normoblasts within the neoplasm. 